\title{
PHYSICAL AND CHEMICAL PROPERTIES OF PULP WASTE FOR ENERGY PURPOSES
}

\author{
Magdalena Dabrowska $^{1}$, Suvi Kuittinen ${ }^{2}$, Ari Pappinen ${ }^{2}$, Adam Swietochowski ${ }^{1}$ \\ ${ }^{1}$ Warsaw University of Life Sciences, Poland; ${ }^{2}$ University of Eastern Finland, Finland \\ magdalena_dabrowska@sggw.pl, adam_swietochowski@sggw.pl
}

\begin{abstract}
In pulp and paper industry biomass rich in energy is represented by pulping liquors, wood wastes, sludge and rejects. Many pulp and paper mills produce more than half of their energy needs from biomass fuels recovered from solid pulp and paper wastes. The end-products of conversion of these wastes are solid, liquid or gaseous fuels and moreover, in most cases, the valuable and ecological fertilizer. The proper method of biomass conversion depends on its structure and chemical composition, which includes hemicellulose, cellulose and lignin content.. Pulp and paper industry generate a lot of quantities of valuable biomass as wastes in all stages of the process. Therefore, this paper reviews the current state of using waste from pulp and paper industry as a fuel for energy purposes. For investigation, the materials from four different types of pulp waste were used. Pulp waste I contained knots and barks and was a product of chemical and semi-chemical pulp processes and of mechanical pulp manufacture, pulp waste II contained final fiber waste sludge from kraft mill, pulp waste III contained fiber sludge from board mill and pulp waste IV contained final fiber waste sludge from board mill. The article contains a description of physical properties of pulp wastes such as: moisture content, density, gross and net calorific values. A chemical analysis includes determination of dry matter, element composition and contents of ash, glucan, xylan, mannan and lignin. It was found that residues from mechanical and chemical pulping varied in the origin and stage of production, had similar chemical composition, differed in a narrow range. Pulp waste materials are rich in sugars of above $52 \%$, reaching a value of approximately $71 \%$, depending on the sample taken at different stages of processing. Net calorific values for all tested raw materials were high in the range from 19.8 to $20.5 \mathrm{MJ} \cdot \mathrm{kg}^{-1}$ and should be considered as feedstock suitable to generate enough energy.
\end{abstract}

Keywords: pulp waste, paper waste, properties, biomass conversion.

\section{Introduction}

Significant increase of fossil fuel prices causes a development in investments of renewable energy sectors. Alternatives for fossil fuels cover a wide range of biomass and waste processing. The proper method of biomass conversion depends on its structure and chemical composition, which includes hemicellulose, cellulose and lignin content. To the most used methods of conversion the biomass to energy gasification, esterification, pyrolysis, methane fermentation and agglomeration processes can be included. The end-products of these conversions are solid, liquid or gaseous fuels and moreover, in most cases, the valuable and ecological fertilizer. Knowledge of the composition of each material is crucial to efficiently operate the system and produce energy.

European and country level legislations are driving the waste sector towards higher efficiencies and recycling. However, complete elimination of generation of residues will never be possible. Nevertheless, as pulp and paper production residues can be managed in a sustainable manner, they can become a valuable raw material for other industries. Pulp and paper industry's role in the national bioenergy production is significant in many European countries. Nowadays, biomass waste streams from the production of fibrous pulps and paper are a source of energy in incineration plants, however, there is more effective use of this kind of biomass such as gasification, production of syngas or methanol [1-3]. Another possibility of effective utilization of pulp waste is anaerobic digestion. Pulp and paper industry generate a lot of quantities of valuable biomass as wastes in all stages of the process: wood preparation, manufacturing, chemical recovery, recycled paper processing and waste water treatment. Waste from pulp and paper industry are sources of organic substances that could be economic and ecologically beneficial, if the proper method of their processing will be chosen. The pulp and paper industry comprises manufacturing enterprises that convert cellulose fibre into a wide variety of pulps, papers and paperboards. Many paper and pulp mills generate more than half of their energy needs from biomass fuels recovered from solid waste and process streams. Biomasses rich in energy, derived from black liquor, wood chips, bark, sawdust, rejects and sludge are the results of atmospheric carbon dioxide accumulated by trees during their growth and transformed into organic carbon substances. By-products and residues from mechanical and chemical pulping include wood, straw and reed residues, fiber rejects and excess sludge from external biological waste water treatment [4]. Several approaches covering the conversion of pulp waste into lignocellulosic valuable material can be found in the literature [5]. However, the pulp and paper industries have the potential for the 
implementation of bio refinery, where it aims to take full advantage of biomass and converting pulp waste. The paper and pulp industry is an energy-intensive, but energy-efficient industry. Energy recovery from wastes of different origin has become a generally accepted alternative to their disposal or incineration. Combined wood waste and sludge generated at the mill are sufficient for combustion demand, because of low heating values resulting from their high moisture and ash contents. The analysis of the calorific value of the above mentioned wastes is important to calculate the combustion efficiency of each waste in order to compare their efficiencies to fossil fuels like coal and oil to ultimately generate enough energy to be used as biofuel.

Waste from pulp and paper industry are a source of organic substance that could be economic and ecologically beneficial, if the proper method of their processing will be chosen. Nowadays, biomass side streams from the production of fibrous pulps and paper are a source of energy in incineration plants, however, there is more effective use of this kind of biomass such as gasification, production of syngas or methanol. Knowledge of the composition of each material is critical to efficiently operate the system of energy production and should lead to the best method of specific waste conversion.

Therefore, the aim of this study was to investigate a basic composition of pulp waste materials and determine their physical properties, including the density and calorific value.

\section{Materials and methods}

For investigation, the materials from four different types of pulp waste were used. Pulp waste I (PW_1) contained knots and barks and was a product of chemical and semi-chemical pulp processes and of mechanical pulp manufacture, pulp waste II (PW_2) contained final fiber waste sludge from kraft mill, pulp waste III (PW_3) contained fiber sludge from board mill and pulp waste IV (PW_4) contained final fiber waste sludge from board mill.

Physical properties of pulp wastes such as: moisture content, density, gross and net calorific values were determined according to standards. Moisture content was determined by the dryingweighing method. The pulp waste was dried in the dryer (Pol-Eko Aparatura, Wodzisław Śląski, Poland) at standard drying temperature of $105^{\circ} \mathrm{C}$ for $24 \mathrm{~h}$ according to the ASAE S358.2 standard. Trials were made for samples of $20 \mathrm{~g}$ in five repetitions for each type of tested materials. Samples were weighed on laboratory scales WSP 600/C (Radwag, Radom, Poland) with an accuracy of $0.01 \mathrm{~g}$. Density of the raw material was determined taking into account a volume of the container and mass of the samples according to the ASAE S269.4 standard in five repetitions. Gross calorific value in three repetitions was determined using KL-10 calorimeter and then using moisture and hydrogen content the net calorific value was calculated. The parameters of the air in the laboratory were monitored: temperature $22 \pm 2{ }^{\circ} \mathrm{C}$, humidity $64 \pm 3 \%$ and pressure $1010 \pm 12 \mathrm{hPa}$.

The total mass balance in these varied materials is the summative analysis of the carbohydrates disclosure into their derivatives together with lignin, extractives, and ash contribution [6-8]. Therefore, a chemical analysis including determination of the dry matter, elements composition and contents of ash, glucan, xylan, mannan and lignin was performed. Ash, extractives, lignin analyses, and sugar analyses from solid materials were determined according to Hayes [9]. In the extractives analysis, both ethanol and water were used and a Dionex Accelerated Solvent Extractor was used. For the Klason acid-soluble lignin (ASL) determination, the NREL method was used [10]. Glucan content was analysed using high-performance liquid chromatography (HPLC).

\section{Results and discussion}

Contents of the main components in the tested samples are presented in Table 1 (data on a dry basis). The results represent the total weight percentage content of the industrial samples collected in the pulp mills.

All tested materials were similar due to the dry organic matter, which was over $92 \%$ in each case (Table 1). The highest amount of total sugars had PW_1 (70.91\%) probably because of the bark and knot content in the raw material. Solid residues from pulp waste combustion are ash and incompletely combusted carbon. The ash content varied considerably $(4.28-7.11 \%)$, as did the content of extractives in pulp and paper waste materials (7.5-10.19\%). The extractives include various chemical compounds that can be extracted with organic solvents, although some are also soluble in water and 
are responsible for characteristics such as odour, colour and flavour of lignocellulosic and are present in small quantities (from 2 to $8 \%$ ) [11]. The mannan content ranged between 2.67 and $8.17 \%$ of the dry matter. Regarding to glucan content, equal to cellulose content in this kind of material, it was very high share in all tested samples, but the highest value was obtained for PW_1 (56.54 \%) and the lowest value $(39.16 \%$ ) was obtained for PW_4 (final fiber sludge sample). Cellulose is the most abundant component in wood and its derivatives.

Table 1

Chemical composition of tested four types of pulp waste

\begin{tabular}{|c|c|c|c|c|c|c|c|c|c|}
\hline Material & $\begin{array}{c}\text { Dry } \\
\text { organic } \\
\text { matter, } \\
\mathbf{\%}\end{array}$ & $\begin{array}{c}\text { Total } \\
\text { sugars, } \\
\mathbf{\%}\end{array}$ & $\begin{array}{c}\text { Glucan, } \\
\mathbf{\%}\end{array}$ & $\begin{array}{c}\text { Xylan, } \\
\mathbf{\%}\end{array}$ & $\begin{array}{c}\text { Mannan, } \\
\mathbf{\%}\end{array}$ & KL, \% & ASL, \% & $\begin{array}{c}\text { Ash, } \\
\mathbf{\%}\end{array}$ & $\begin{array}{c}\text { Extractives, } \\
\mathbf{\%}\end{array}$ \\
\hline PW_1 & 94.81 & 70.91 & 56.54 & 6.82 & 5.52 & 19.10 & 0.51 & 5.19 & 7.5 \\
\hline PW_2 & 92.92 & 52.32 & 43.72 & 4.01 & 2.67 & 19.15 & 2.63 & 7.08 & 10.05 \\
\hline PW_3 & 95.72 & 60.31 & 42.18 & 8.45 & 7.11 & 24.18 & 0.84 & 4.28 & 10.19 \\
\hline PW_4 & 92.89 & 56.48 & 39.16 & 6.26 & 8.17 & 24.87 & 0.81 & 7.11 & 7.71 \\
\hline
\end{tabular}

Lignin is the second component in larger quantities in lignocellulosic and its presence provides all the complexity existing in pulping processes, because it has a quite complex structure [12]. The KL lignin contents for PW_1 and PW_2 samples were similar (19.1 and 19.15\%, respectively) and for PW_3 and PW_4 higher, but similar to each other and were 24.18 and $24.87 \%$, respectively. The ASL lignin content was the highest for PW_2 and it was $2.63 \%$, however for PW_1 it was the lowest content of $0.51 \%$.

For further analysis, the mass balance of the entire industrial process of pulp and paper waste should be carried out taking into account the summative analysis. However, to better understand and evaluate these side streams, the complete characterization of the feedstock, the primary and final pulps, and the main residual stream from each stage of the process are required.

The results of the physical parameters of the tested pulp waste are shown in the Figures 1 and 2. The PW_4 sample was characterised by the highest density of $650 \mathrm{~kg} \cdot \mathrm{m}^{-3}$, however, the scatter of data was narrow in the range from 580 to $650 \mathrm{~kg} \cdot \mathrm{m}^{-3}$. These values were similar to woody biomass and other pulp and paper wastes investigated by other authors [5].

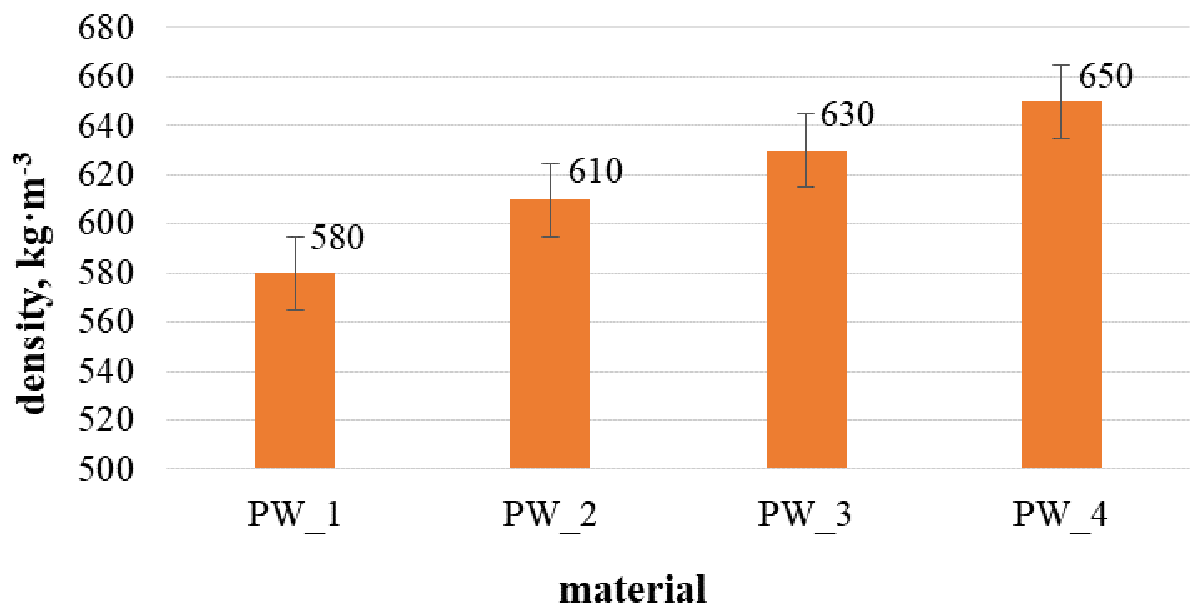

Fig. 1. Density of pulp waste varied in origin and stage of production

Research of the heating value allowed to state that side streams from pulp and paper industry have a high concentration of energy per mass unit for dried materials. The highest value was obtained for PW_3 material, and it was $20.5 \mathrm{MJ} \cdot \mathrm{kg}^{-1}$ and the lowest, but also a high value, was obtained for PW_2 material, and it was $19.8 \mathrm{MJ} \cdot \mathrm{kg}^{-1}$. Compared to other materials, these values are a good indicator of this waste usefulness to further conversion and processing in obtaining and recovering energy. The 
amount of ash in pulp waste strongly affects the heating value. In this study obtained results of the heating value correspond with the ash amounts, what is consistent with literature data [13].

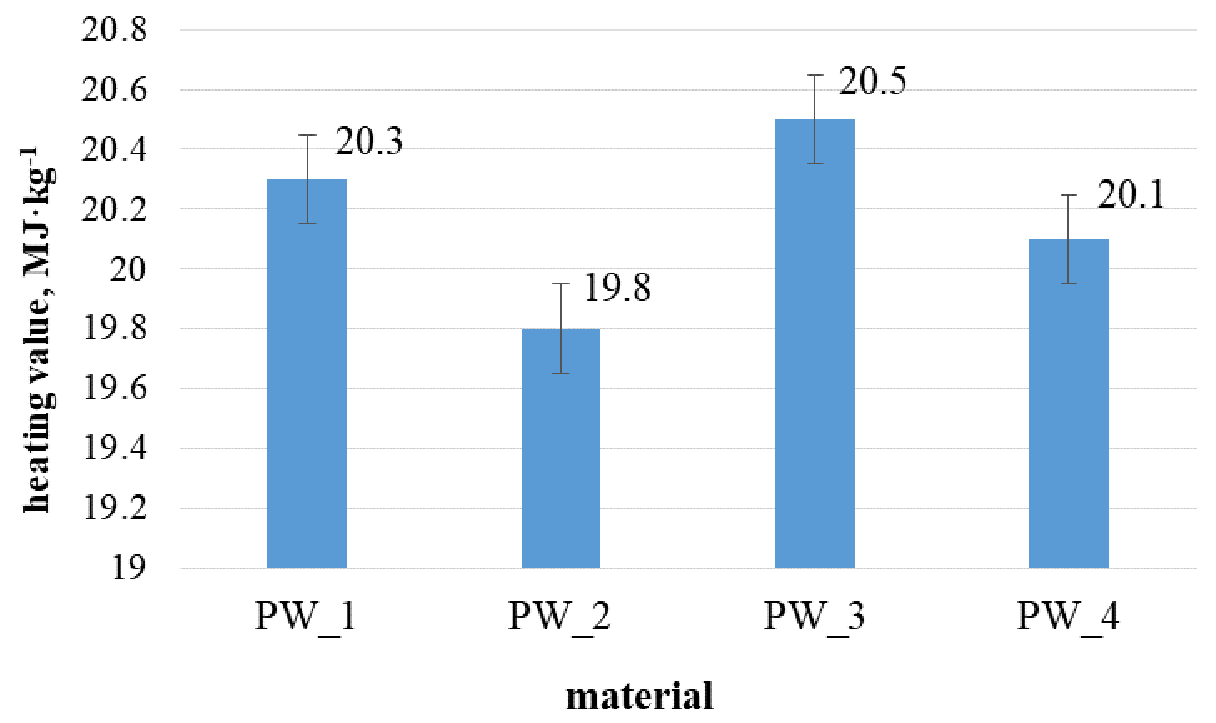

Fig. 2. Heating values of tested pulp wastes

\section{Conclusions}

1. Residues from mechanical and chemical pulping varied in the origin and stage of production had similar chemical composition, differed in a narrow range.

2. Pulp waste materials are rich in sugars of above $52 \%$, reaching a value of approximately $71 \%$, depending on the sample taken at different stages of processing.

3. Heating values for all tested raw materials were high in the range from 19.8 to $20.5 \mathrm{MJ} \cdot \mathrm{kg}^{-1}$ and should be considered as feedstock suitable to generate enough energy.

\section{References}

[1] Pelegrini M. Plates made with solid waste from the recycled paper industry. Waste Management, Issue 30, 2010, pp. 268-273.

[2] Agulló L.A.A.G.T. Study of the use of paper manufacturing waste in plaster composite mixtures. Building and Environment, Issue 41, 2006, pp. 821-827.

[3] Breslin V.S.U.B.C. Long-term engineering properties of recycled plastic lumber used in pier construction.. Resources, Conservation and Recycling, Issue 23, 1998, pp. 243-258.

[4] Ismail Demir M.S.B.M.O. Utilization of kraft pulp production residues in clay brick production. Building and Environment, Issue 40, pp. 2005, 1533-1537.

[5] Chakar F.S., Ragauskas A.J. Review of current and future softwood kraft lignin process chemistry, Industrial Crops and Products, vol. 20, no. 2, 2004, pp. 131-141.

[6] Santana M.A.E., Okino E.Y.A. Chemical composition of 36 Brazilian Amazon forest wood species, Holzforschung, vol. 61, no. 5, 2007, pp. 469-477.

[7] Alves E.F., Bose S.K.,. Francis R.C, Colodette J.L., Iakovlev M., van Heiningen A. Carbohydrate composition of eucalyptus, bagasse and bamboo by a combination of methods, Carbohydrate Polymers, vol. 82, no. 4, 2010, pp. 1097-1101.

[8] Kaar W.E., Cool L.G., Merriman M.M. The complete analysis of wood polysaccharides using HPLC, Journal of Wood Chemistry and Technology, vol. 11, no. 4, 1991, pp. 447-463.

[9] Hayes D.J.M. Development of near infrared spectroscopy models for the quantitative prediction of the lignocellulose components of wet Miscanthus samples. Bioresource Technology 119, 2012, pp. 393-405.

[10] Sluiter A., Hames B., Ruiz R., Scarlata C., Sluiter J., Templeton D., Crocker D. Determination of structural carbohydrates and lignin in biomass. Technical Report NREL/TP-2012, 2012, $18 \mathrm{p}$. 
[11] Sjöström E., Westermark U. Chemical composition of wood and pulps: basic constituents and their distribution. In: Eds. Sjöström, E.; Alén R. Analytizal methods in wood chemistry, pulping and papermarking. Helsinki: Springer series in wood Science, 1999, p.1-20.

[12] Ralph J., Lundquist K. Brunow G., Lu F., Kim H., Schatz P.F., Marita J.M, Hatfield R.D., Ralph S.A., Christensen J.H., Boerjan W. Lignins: Natural polymers from oxidative coupling of 4hydroxyphenyl-propanoids. Phytochemistry, vol. 3, 2004, pp. 29-60.

[13] Scott G.M., Smith A. Sludge characteristics and disposal alternatives for the pulp and paper industry. In: Proceedings of the 1995 International environmental conference; 1995 May 7-10; Atlanta, GA. Atlanta, GA: TAPPI PRESS: 269-279. 